\title{
A Systematic Review on Cannabis Hyperemesis Syndrome and Its Management Options
}

\author{
Helen Senderovich ${ }^{a}$ Preet Patel $^{b}$ Briam Jimenez Lopez ${ }^{c}$ Sarah Waicus ${ }^{d}$ \\ aDepartment of Family and Community Medicine, Geriatrics and Palliative Care, Baycrest Health Sciences, University \\ of Toronto, Toronto, ON, Canada; 'bniversity of Waterloo, Waterloo, ON, Canada; 'Department of Medicine, Queen's \\ University, Kingston, ON, Canada; ${ }^{\mathrm{d} S}$ chool of Medicine, Trinity College Dublin, Dublin, Ireland
}

\section{Highlights of the Study}

- The chronic longstanding use of cannabis has been implicated in causing refractory nausea and vomiting named cannabinoid hyperemesis syndrome.

- Treatments such as topical capsaicin, haloperidol, droperidol, benzodiazepines, propranolol, and aprepitant have shown symptom relief.

- Rapid recognition, diagnosis, and knowledge translation of the available treatment options for cannabinoid hyperemesis syndrome is warranted, especially in older adults with comorbidities where pharmacological interactions can mask or exacerbate the syndrome.

\section{Keywords}

Cannabinoid hyperemesis syndrome $\cdot$ Vomiting $\cdot$ Nausea . Cannabinoids

\begin{abstract}
Introduction: Several forms of cannabinoids are currently being used to manage nausea and vomiting (N/V). Emerging cases of refractory N/V associated with chronic cannabis use among adults and older patients have been reported named cannabis hyperemesis syndrome (CHS). CHS is a condition that leads to repeated and severe N/V in long-term users of cannabinoids. Objective: The aim of this study was to outline current treatments for the management of CHS. Methods: A systematic review was conducted using PubMed, Ovid MEDLINE, Cochrane Central, EMBASE, and Google Scholar. Databases were used to search for articles on CHS published from
\end{abstract}

January 2009 to June 2021, yielding 225 results of which 17 were deemed relevant and underwent review by 2 separate reviewers. Results: The duration of cannabis administration ranged between 6 months to 11 years may precipitate symptoms of CHS. The Rome IV diagnostic criteria of $\mathrm{CHS}$ require cannabinoid use and persistence of N/V symptoms for at least the past 6 months. Cannabis cessation is noted to be the most successful management, but other treatments also demonstrated symptom relief; these include hot water hydrotherapy, topical capsaicin cream, haloperidol, droperidol, benzodiazepines, propranolol, and aprepitant administration. Conclusion: More research on CHS is needed to enhance knowledge translation, education, and create awareness in the medical community on the side effects of cannabinoids and to propose the best treatment options.

(c) 2021 The Author(s).

Published by S. Karger AG, Basel karger@karger.com www.karger.com/mpp

Karger $\stackrel{\text { ' }}{5}$

GOPEN ACCESS
(C) 2021 The Author(s)

Published by S. Karger AG, Basel

This is an Open Access article licensed under the Creative Commons Attribution-NonCommercial-4.0 International License (CC BY-NC) (http://www.karger.com/Services/OpenAccessLicense), applicable to the online version of the article only. Usage and distribution for commercial purposes requires written permission.
Correspondence to:

Helen Senderovich, hsenderovich @ baycrest.org 


\section{Introduction}

Cannabis is the most-used recreational drug worldwide, and its incidence of use continues to grow over time [1]. Approximately 192 million individuals use cannabis in any of its forms at least once a year [2]. Cannabis is a general term that refers to the products derived from the plant genus Cannabis. The active ingredients of plantbased cannabis are known as cannabinoids and include the psychoactive ingredient tetrahydrocannabinol (THC) and cannabidiol [3]. Cannabinoids have become an area of interest for the management of pain, and nausea and vomiting (N/V) [1-3]. Recent research has shown recurrent cases of $\mathrm{N} / \mathrm{V}$ with distinct pathogenesis associated with chronic cannabis usage, known as cannabis hyperemesis syndrome (CHS) [3]. CHS is the result of ingesting high amounts of cannabis from a botanical or synthetic source [4]. Recreational use of cannabis is most common among individuals aged 18-25 years, where cannabis-induced N/V has a high incidence [5]. The adult population was defined as 18 years and older, with the older adult population defined as 65 years and older. The condition can cause distress for the patient, in addition to repetitive hospitalization, and impacts costs of healthcare [6]. The episodes of extended N/V in CHS may last from a few hours, days, or weeks [7]. The Rome IV criteria defines CHS as stereotypical episodic vomiting, after prolonged excessive cannabis use with symptom onset $>6$ months, which is relieved by sustained cessation of cannabis [8]. A demonstration of the grading of N/V and the side effects associated with the respective grading can be found in Table 1.

Nabilone, sold under the brand name Cesamet ${ }^{\odot}$, is a synthetic cannabinoid with therapeutic use as an antiemetic and as an adjunct analgesic for neuropathic pain. Nabilone mimics THC, the primary psychoactive compound found naturally occurring in cannabis. Despite the current acceptance of Nabilone as a treatment option for $\mathrm{N} / \mathrm{V}$ in patients with CHS, there is a lack of data regarding the side effects of its prolonged use such as accumulation and toxicity, resulting in exacerbation of $\mathrm{N} / \mathrm{V}$ rather than curing it.

Although the exact mechanism of action for cannabinoids are yet to be determined, there are 3 main hypotheses regarding CHS gastrointestinal cannabinoid receptors 1 (CB1), overriding cannabinoid lipid buildup and genetic polymorphisms in the P450 system. Gastrointestinal CB1 receptors reduce gastric emptying causing the N/V seen in CHS $[5,9]$. Cannabinoid lipid buildup can also occur as THC is lipid soluble. During stress, fat is broken down leading to the release of large amounts of THC causing CHS symptoms $[10,11]$. Further, genetic polymorphisms in the metabolic $\mathrm{P} 450$ enzymes lead to a change in the metabolic rate of THC breakdown causing hyper or hyposensitivity $[12,13]$. In-depth mechanisms for different CHS hypotheses are presented in Figure 1.

Proving the emetic and antiemetic effects of cannabinoids is difficult due to the overlapping nature of the symptoms with other conditions such as cyclic vomiting syndrome, viral gastroenteritis, and bulimia nervosa [14]. Furthermore, it was only categorized as a functional gastrointestinal disease in 2016 [14]. This syndrome produces consequences ranging from volume loss to esophagus rupture [15]. With worldwide increase in cannabinoid use due to legalization, cases of CHS are increasing [16]. Therefore, it is important for clinicians to recognize CHS.

\section{Objective}

The aim of this systematic review was to highlight current management options for CHS as a potential adverse effect of long-term cannabis use in adults and older populations.

\section{Methods}

A systematic review was conducted by 2 independent researchers using PubMed, Ovid MEDLINE, Cochrane Central, EMBASE and Google Scholar. For each study, the keywords "cannabinoid hyperemesis syndrome," "nausea," "vomiting," and "cannabinoids" were utilized in the search. Eligibility assessment was performed by the independent reviewers (H.S. and S.W.) and disagreements were resolved by consensus. A data extraction excel sheet was developed and used to compile and summarize the relevant studies. Inclusion criteria were established in line with the study objective, where relevant articles underwent data extraction and analysis. Inclusion and exclusion criteria can be found in Table 2. The full electronic search history is shown in Figure 2.

\section{Inclusion Criteria}

We included systematic reviews, retrospective cohorts, case reports, and randomized-controlled trials (RCTs), written in the English language; from January 2009 to June 2021 that described the use of cannabinoids and CHS in adult and older populations (18 years and 
Table 1. N/V grading scale

\begin{tabular}{|c|c|c|c|c|}
\hline \multicolumn{5}{|l|}{ N/V grading scale } \\
\hline grade 1 (mild) & grade 2 (moderate) & grade 3 (severe) & grade 4 (life threatening) & grade 5 \\
\hline \multicolumn{5}{|l|}{ Nausea } \\
\hline $\begin{array}{l}\text { Loss of appetite without } \\
\text { alteration in eating habits }\end{array}$ & $\begin{array}{l}\text { Oral intake decrease without } \\
\text { significant weight loss, } \\
\text { dehydration, or malnutrition }\end{array}$ & $\begin{array}{l}\text { Inadequate oral caloric or fluid intake; tube } \\
\text { feedings, TPN, or hospitalization may be } \\
\text { indicated }\end{array}$ & - & - \\
\hline \multicolumn{5}{|l|}{ Vomiting } \\
\hline $\begin{array}{l}1-2 \text { Episodes (separate by } 5 \\
\min \text { ) in } 24 \mathrm{~h}\end{array}$ & $\begin{array}{l}3-5 \text { episodes (separated by } \\
5 \mathrm{~min} \text { ) in } 24 \mathrm{~h}\end{array}$ & $\begin{array}{l}\geq 6 \text { episodes (separated by } 5 \mathrm{~min} \text { ) in } 24 \mathrm{~h} \text {; tube } \\
\text { feeding, TPN, or hospitalization indicated }\end{array}$ & $\begin{array}{l}\text { Life-threatening } \\
\text { consequences; urgent } \\
\text { intervention indicated }\end{array}$ & Death \\
\hline
\end{tabular}

N/V, nausea and vomiting.

Table 2. Inclusion and exclusion criterion examining CHS in the adult population

\begin{tabular}{ll}
\hline Inclusion criteria & Exclusion criteria \\
\hline Qualitative reviews, retrospective cohort, case studies and RCTs involving CHS & Studies published out of the period of Jan 2009 to Jun 10, 2021 \\
\hline English language articles & Foreign language articles \\
Articles from Jan 2009 to Jun 2021 & Articles assessing recreational cannabinoid use \\
Studies describing the use of medicinal and recreational cannabinoid use & Articles not assessing CHS as the primary focus \\
Statistical significant $(p<0.05)$ and nonsignificant RCT and retrospective cohort studies & Adolescent and youth populations (under the age of 18) \\
Individuals aged 18 years old and older & \\
\hline
\end{tabular}

CHS, cannabis hyperemesis syndrome; RCT, randomized-controlled trial.

Fig. 1. Mechanisms of CHS. CHS, cannabis hyperemesis syndrome; CB1, cannabinoid receptors 1; CTZ, chemoreceptor trigger zone; THC, tetrahydrocannabinol.

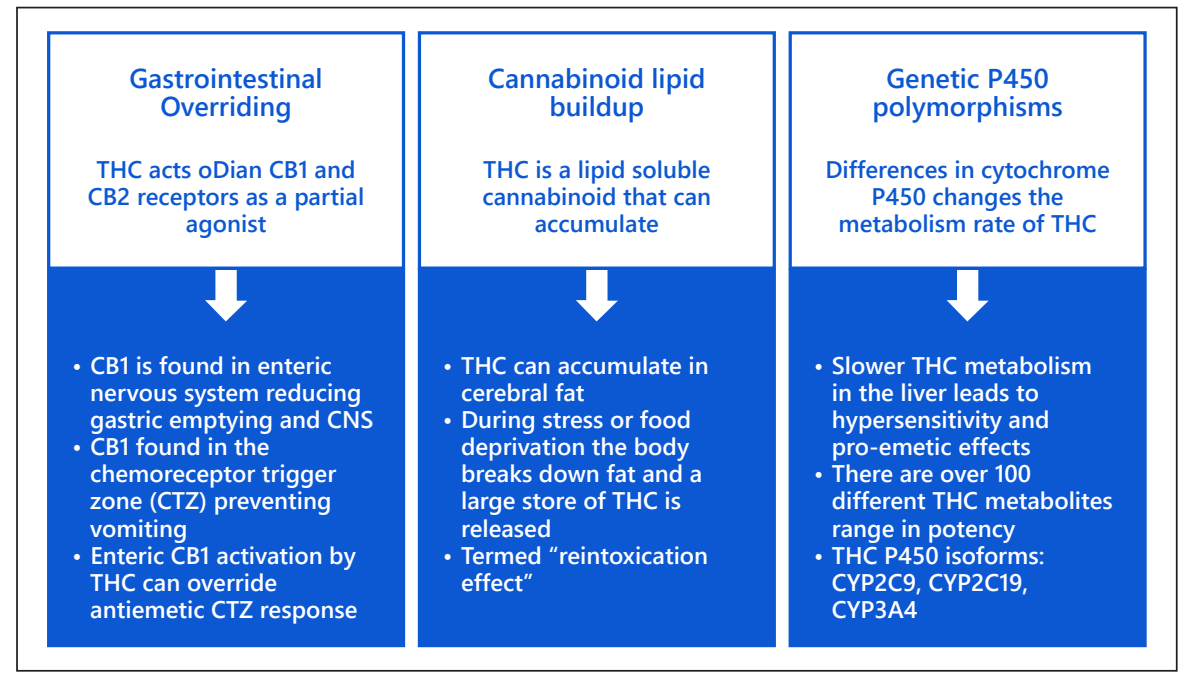

older) were included. The PICO tool was used to inform and guide the keywords used in the search. We assessed adults and older populations with N/V who were using recreational or medicinal cannabinoids. The management options included pharmacological treatments and water hydrotherapy which were compared to placebo.
The outcomes included the effectiveness of the interventions seen in decreasing N/V induced by cannabinoids. The age range of $18-85$ years was chosen to include all adults and the older population, as this age group falls under the category of most frequent cannabis users and thus can develop CHS as well. 
Fig. 2. PRISMA flow diagram search history. RCT, randomized control trial; CHS, cannabis hyperemesis syndrome.
Identification of studies via databases and registers

Screened as potentially

elevant studies $(n=225)$

MEDLINE $(n=32)$

Cochrane $(n=8)$

EMBASE $(n=20)$

PubMed $(n=125)$

Google Scholar $(n=40)$

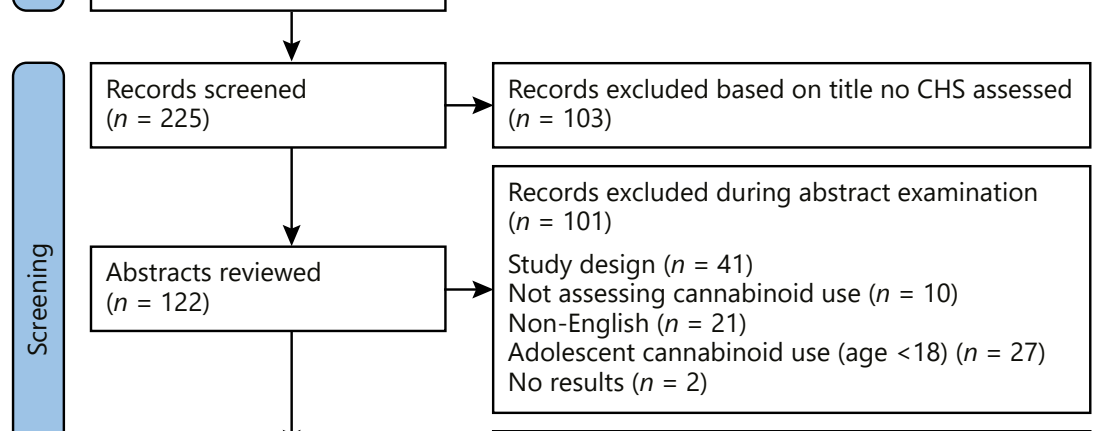

Full-texts reviewed $(n=21)$ $(n=4)$

Duplicates $(n=4)$

Studies included in review

$(n=17)$

Case report or series $(n=9)$

$\operatorname{RCT}(n=2)$

Retrospective $(n=2)$

Systematic review $(n=4)$

\section{Exclusion Criteria}

The exclusion criteria included studies published outside the time period of January 2009 to June 2021; nonEnglish language articles that had poor translations; articles not assessing cannabinoid use and CHS as the primary focus; adolescent and youth populations under the age of 18 years were excluded.

\section{Results}

\section{Search Results}

Relevant articles underwent data extraction and analysis where conclusions of this review are drawn from. There were 225 articles identified and screened, and 103 records were excluded based on the title not including the term CHS. 122 Abstracts were then reviewed, and 101 were eliminated due to study design outside of the inclusion criteria $(n=41)$, not assessing cannabinoid use $(n=10)$, non-English studies $(n=21)$, population age $<18$ years old $(n=27)$ and articles that had no results $(n=2)$. Twenty-one full-text articles were then reviewed, and duplicates were excluded $(n=$ 4). Overall, 17 articles met the final inclusion criteria and warranted analysis: case reports or series $(n=9)$, RCT $(n=2)$, retrospective cohort studies $(n=2)$ and systematic reviews $(n=4)$. The full search strategy and results are presented in Figure 2.

Corroborative themes were identified, and the authors responsible for the contributing research were cited appropriately. All additional sources added to the literature search were referenced in the article. The Cochrane Risk of Bias Tool was used to assess the risk of bias in RCTs found in Table 3. An additional version of the tool for assessing the risk of bias in non-randomized studies can be found in Table $4[17,18]$.

\section{Management of CHS}

The best method to alleviate symptoms in all studies reviewed was the discontinuation of cannabinoid use. In addition, there were 7 management-described op- 
Table 3. Risk of bias in RCT

\begin{tabular}{|c|c|c|c|c|c|c|}
\hline Study & $\begin{array}{l}\text { random sequence } \\
\text { generation }\end{array}$ & $\begin{array}{l}\text { allocation } \\
\text { concealment }\end{array}$ & $\begin{array}{l}\text { Performance bias } \\
\text { blinding of participants } \\
\text { and personnel }\end{array}$ & $\begin{array}{l}\text { Detection bias } \\
\text { blinding of } \\
\text { outcome assessor }\end{array}$ & $\begin{array}{l}\text { Attrition bias } \\
\text { incomplete } \\
\text { outcome data }\end{array}$ & $\begin{array}{l}\text { Reporting bias } \\
\text { selective } \\
\text { reporting }\end{array}$ \\
\hline Dean et al. [22] & Low $^{*}$ & Low & Low & Low & Some concern* & Low \\
\hline Ruberto et al. [32] & Low & Low & Low & Low & Low & Low \\
\hline
\end{tabular}

RCT, randomized-controlled trial. * Low, low risk of bias; Some concern, some concerns of bias .

Table 4. Risk of bias in non-randomized interventional studies

\begin{tabular}{|c|c|c|c|c|c|c|c|}
\hline \multirow[t]{2}{*}{ Study } & \multicolumn{2}{|c|}{ Pre-intervention } & \multirow{2}{*}{$\begin{array}{l}\text { At intervention } \\
\text { bias in } \\
\text { classification of } \\
\text { interventions }\end{array}$} & \multicolumn{4}{|l|}{ Post-intervention } \\
\hline & $\begin{array}{l}\text { bias due to } \\
\text { confounding }\end{array}$ & $\begin{array}{l}\text { bias in selection } \\
\text { of participants } \\
\text { into the study }\end{array}$ & & $\begin{array}{l}\text { bias due to } \\
\text { deviations from } \\
\text { intended } \\
\text { interventions }\end{array}$ & $\begin{array}{l}\text { bias due to } \\
\text { missing data }\end{array}$ & $\begin{array}{l}\text { bias in } \\
\text { measurement of } \\
\text { outcomes }\end{array}$ & $\begin{array}{l}\text { bias in selection } \\
\text { of the reported } \\
\text { result }\end{array}$ \\
\hline Wagner et al. [24] & Moderate* & Moderate & Low* & Moderate & Low & Moderate & Serious* \\
\hline Yusuf et al. [25] & Moderate & Moderate & Low & Low & Low & Low & Moderate \\
\hline Lee et al. [28] & Moderate & Serious & Low & Moderate & Moderate & Moderate & Serious \\
\hline
\end{tabular}

$\mathrm{RCT}$, randomized-controlled trial. * Low, low risk of bias compared to well-performed RCT; Moderate, low to moderate risk of bias; Serious, serious risk of bias.

tions to control N/V induced by cannabis: (i) hot water hydrotherapy; (ii) topical capsaicin; (iii) droperidol; (iv) benzodiazepines; (v) haloperidol; (vi) propranolol; and (vii) aprepitant. The results are summarized in online supplementary Table 1 (for all online suppl. material, see www.karger.com/doi/10.1159/000520417).

\section{Hot Water Hydrotherapy}

Taking hot baths has been shown to provide temporary relief of N/V as THC disrupts thermoregulation [19]. Hot water hydrotherapy is a common self-treatment for patients diagnosed with CHS as it can cause redirection of blood flow from the enteric system to the skin, leading to $\mathrm{N} / \mathrm{V}$ ' combined with the activation of transient receptor potential vanilloid subtype 1 (TRPV1) [19]. Activation of TRPV1 leads to a reduction in the release of substance $\mathrm{P}$, a neuropeptide associated with inflammation and pain, in nerve endings. Over time, the TRPV1 can become unresponsive due to chronic exposure to THC, resulting in pain caused by an increase in substance $P$ [19]. A case report by Portman and Donovan [20] described a 62-year-old man who was on chemotherapy for long-term malignancy and had a history of recurrent $\mathrm{N} / \mathrm{V}$, managed with cannabinoids as an antiemetic. How- ever, cannabis use became pro-emetic and resulted in multimer admissions to the ED. Traditional antiemetics and opioids were ineffective; the only effective treatment was immersion in hot water showers and complete cannabinoid aversion [20]. It should be noted that only qualitative evidence presented as a narrative review was found as evidence related to hot water hydrotherapy treatment.

\section{Topical Capsaicin}

Topical capsaicin cream has shown short-term success in patients suffering from CHS [21]. Capsaicin may be similar to hot water hydrotherapy, causing redirection of blood flow from the enteric system to the skin and leading to activation of TRPV1 receptors, reducing substance $P$ [20]. In all studies examined, capsaicin was applied to the abdomen. A novel piloted RCT conducted by Dean et al. [22] examined topical $0.1 \%$ capsaicin versus placebo cream applied on the anterior abdominal/pre-umbilical region. The authors reported a $46 \%$ reduction in nausea from baseline using the visual analog scale at $60 \mathrm{~min}$ from baseline in the capsaicin arm versus $24.9 \%$ in the placebo arm [22]. It was concluded that the antiemetic effect of capsaicin was more efficacious at 60 min compared to 30 min measured from the initial administration of capsa- 
icin [22]. Individual case studies have shown improvement in N/V and discharge within hours of admission when patients were administered $0.075 \%$ capsaicin on the abdominal region [23]. A retrospective cohort examined 43 patients within the emergency department (ED), patient's length of stay (LOS) was reduced with variable capsaicin $(0.025-0.1 \%)$ administered on the abdomen by a median of $22 \mathrm{~min}$, furthermore, patients received fewer additional medications such as opioids if capsaicin was utilized ( $p=0.015$ ) [24]. A recent retrospective cohort study revealed that $0.025-0.15 \%$ capsaicin cream was associated with a shorter LOS in the ED when administered earlier upon admission (4.83 h vs. $7.09 \mathrm{~h}, p=0.01$ ) [25]. A 41-year-old female presented to the ED with severe N/V unresponsive to typical antiemetics such as pantoprazole and morphine [26]. Topical $0.1 \%$ capsaicin application 3 times daily on the epigastric region provided dramatic relief of N/V within $24 \mathrm{~h}$ with no return to the ED [26].

It should be noted that the case series using capsaicin cream had a small patient sample cohort of only 1-4 patients; as a result, success in larger cohorts may be questioned $[23,26]$. The RCT conducted by Dean et al. [22] presented with overall a low risk of bias; however, there were some concerns related to attrition bias, as one individual ended their involvement early. Despite the appropriate statistical methods used in the study conducted by Wagner et al. [24], the subgroup analysis presented a serious risk of bias due to a small sample that may contain unbalanced prognostic factors. Furthermore, in this study, a reduction of opioid and other medications use was reported in conjunction which may confine the results as opioids may lead to N/V, and upon cessation contribute to an effect that is not discernible from other interventions, such as the capsaicin cream [24]. The retrospective cohort conducted by Yusuf et al. [25] had a moderate bias in selecting patients in the $\mathrm{ED}$, as there was selective reporting of patient outcomes, as only the LOS in the ED was measured.

\section{Droperidol}

Droperidol is a short-acting dopamine antagonist that is most commonly used as an antiemetic and antipsychotic agent [26]. A systematic review conducted by Furyk et al. [27] examined the role of droperidol in the management of CHS. It was found that $0.625-2.5 \mathrm{mg}$ of IV droperidol was the only treatment that showed statistically significant $(p<0.05)$ differences in the visual analog scale compared to placebo in 48 patients [27]. Current evidence has shown droperidol administration for CHS pa- tients results in a shorter LOS in the hospital, decreased necessity of other antiemetics and showed a significant decrease in nausea severity from baseline when compared to a placebo [28]. Lee et al. [28] reviewed 76 cases of which 37 were treated with droperidol, and 39 received no treatment. The median stay in the hospital for the treatment group was significantly lower than that of the no treatment group ( $6.7 \mathrm{~h}$ vs. $13.9 \mathrm{~h}, p=0.014$ ) [28]. It should be noted there was serious bias associated with the selection of participants and reporting of results in the retrospective study conducted by Lee et al. [28].

\section{Benzodiazepines}

A case study which examined clonazepam in treatment-resistant individuals with CHS revealed that 2 doses of $0.5 \mathrm{mg}$ of clonazepam led to rapid cessation of adverse symptoms, complete symptomatic relief and discharge within $24 \mathrm{~h}$ after administration [29]. It should be noted that the evidence for benzodiazepine use in CHS is limited, as there was only 1 case study reported with only 4 patients who experienced N/V relief after administration of benzodiazepines [29].

\section{Haloperidol}

Haloperidol, an antipsychotic has been used in the management of N/V in severe CHS cases [28, 29]. A case reported by Inyat et al. [30] revealed that $1 \mathrm{mg}$ followed by 2 doses of $2 \mathrm{mg}$ of haloperidol relieved N/V in a patient experiencing resistant CHS. The single patient reported complete resolution of refractory N/V and abdominal pain after administration of the above schedule and 1 month follow up revealed no recurrent symptoms [30]. A case series reported by Witsil and Mycyk [31] found $5 \mathrm{mg}$ of haloperidol administered via intravenous (IV) resulted in successful relief of N/V for 4 patients in the ED. A recent RCT conducted by Ruberto et al. [32] examined haloperidol and ondansetron use for CHS. It was found that 0.05 or $0.1 \mathrm{mg} / \mathrm{kg}$ of Haldol was superior to ondansetron in decreasing $\mathrm{N} / \mathrm{V}$ measured with the visual analog scale ( $p=0.01)$ and a shorter ER departure $(p=0.03)$; however, there were 2 cases of dystonia with the higher dose of haloperidol [32]. A single case report of an 18-year-old woman who presented to the ED with refractory $\mathrm{N} / \mathrm{V}$, unwilling to discontinue recreational cannabinoid use agreed to initiate a trial of $5 \mathrm{mg}$ haloperidol daily for 3 weeks [33]. There were no adverse effects reported and there was a complete cessation of N/V for this patient [33].

It should be noted that the majority of evidence found for haloperidol were case studies, which had limited gen- 
eralizability [30, 31, 33]. However, the RCT by Ruberto et al. [32] was found to have low overall bias, as there was appropriate cohort randomization, allocation concealment, and blinding of participants and outcome assessors without selective reporting of haloperidol used for CHS.

\section{Propranolol}

Richards and Dutzak [34] presented a single case study that examined an extreme case of CHS in the ER who had intractable $\mathrm{N} / \mathrm{V}$, abdominal discomfort and who was unresponsive to standard antiemetics. One milligram followed by $1 \mathrm{mg}$ IV injections of propranolol $1 \mathrm{~h}$ apart led to rapid termination of $\mathrm{N} / \mathrm{V}$ and complete resolution of hyperemesis after the second injection [34]. It should be noted there was limited evidence for propranolol use as it was the only case study we found involving a single patient [34].

\section{Aprepitant}

Aprepitant is a Neurokinin 1 (NK1) receptor antagonist and similarly to capsaicin is involved in the regulation of substance $\mathrm{P}$ to alleviate N/V in CHS [35]. A case report described by Parvataneni et al. [35] revealed a 30 -year-old female with intermittent N/V who was unresponsive to conventional emetics such as ondansetron. The only treatment the patient responded well to was aprepitant. She was discharged symptom-free $24 \mathrm{~h}$ later after the administration of aprepitant [35]. A major limitation of this case report is that the dosage of aprepitant was not described.

\section{Discussion}

Chronic cannabinoid usage can lead to recurrent N/V with distinct pathogenesis, known as CHS. There is a need for awareness among the medical community about what cannabis can and cannot do as CHS can lead to death [36]. Three mechanisms have been proposed for the development of CHS; these are gastrointestinal CB1 overriding, cannabinoid lipid buildup, and genetic polymorphisms in the P450 system. The exact mechanism, however, remains unknown, and it is out of scope for this review to explore it further.

Currently, there is no reliable management regime for patients with CHS with the exception of complete cessation of cannabis and response to conventional antiemetics is insufficient. Several treatments have been described to relieve N/V in CHS; however, there are limited controlled data to support management decisions. Topical capsaicin

Management of Cannabis Hyperemesis Syndrome and haloperidol are currently the only treatment with efficacy validated in RCTs $[22,32]$. Capsaicin is inexpensive, has shown positive drug-drug interactions with co-administered medications, and has led to decrease opioid requirement/usage, therefore may be feasible for $\mathrm{CHS}$ treatment and decrease unnecessary healthcare costs and visits [19, 21-26]. Haloperidol showed improvements in $\mathrm{N} / \mathrm{V}$ and decreased the LOS in the ED; however, caution should be exercised as it has been shown to cause acute dystonia in higher dosages [30-33]. Other pharmacological interventions, such as droperidol used in the ED for the treatment of CHS, showed accelerated discharge which may help preserve ED resources $[27,28]$. Propranolol has also shown relief in N/V for individuals with severe recurrent CHS [34]. Aprepitant was found to rapidly relive N/V in patients resistant to traditional antiemetics [35].

Factors such as persistent stigma, conflicting regulations, research barriers, and scarcity among medicinal cannabinoids, which arises from poor awareness in patients, healthcare professionals, and stakeholders, can hinder the successful integration of cannabinoids in multiple settings [1]. Due to the growing use of cannabinoid integrative medicines, healthcare professionals must be cognizant that N/V in patients undergoing prolonged cannabis treatment may develop cannabinoid toxicity and CHS. N/V induced by cannabinoids may be masked by N/V related to cancer or side effects of chemotherapy drugs [5]. This awareness may help reduce, identify and effectively manage polypharmacy and cannabinoid-related side effects.

An example of chronic medicinal cannabis administration is cancer treatment. Cannabis is often used by cancer patients as a self-managing strategy with common routes of administration being concentrated oil capsules, smoking and oromucosal spray [37]. Studies have shown that 1 in 5 patients used cannabis within the preceding 6 months, and 1 in 8 patients used cannabis for at least one cancer-related symptom [38]. Cannabinoids are mostly used in cancer patients to manage symptoms such as chemotherapy-induced $\mathrm{N} / \mathrm{V}$, severe pain, muscle spasms, and cachexia [39]. Cannabinoids such as THC and nabilone provided significant $(p<0.01)$ antiemetic effects for (chemotherapy-induced $\mathrm{N} / \mathrm{V}$ ) compared to placebo; however, cannabinoids were comparable to other antiemetic drugs such as prochlorperazine, domperidone, and alizapride [40,41]. Side effects were more profound in older patients [42]. Drug interactions between chemotherapy drugs and cannabinoids can lead to undesirable adverse events. For example, cisplatin and paclitaxel can reduce drug clearance, resulting in delayed metabolism of Cesamet leading to toxic levels of THC causing CHS [43]. 
Compulsive hot water bathing can be an important marker for the diagnosis of CHS [5]. Currently, there are high levels of misdiagnosis of CHS. Conditions can overlap or mask CHS including cyclic vomiting syndrome, eating disorders, or drug-seeking behavior [44]. Knowledge of pharmacological treatments for managing $\mathrm{CHS}$ may lessen the burden of ED resources with the recurring admission of patients with CHS [20, 23, 25, 28, 31, 33, 35].

Furthermore, indications, contraindications, and drug-drug interaction should be kept in mind and risks versus benefits weighed in older adults with multiple comorbidities while considering the management options. In older populations, benzodiazepines should be used with caution in the management of CHS due to the potential risk of addiction, cognitive impairment, development of delirium, and falls [45]. Haloperidol should also be used with caution in patients with dementia and Parkinson's disease, as dopamine blockade can dramatically worsen symptoms causing extrapyramidal side effects and incapacitation [46]. Furthermore, propranolol in patients with chronic obstructive pulmonary disease (COPD) and sinus bradycardia should be avoided, as it worsens bronchoconstriction and bradycardia [47]. Awareness in the public and healthcare professionals about the risk of the development of CHS in prolonged cannabis users will help fill existing knowledge gaps.

\section{Limitations}

Only 2 RCTs have investigated topical capsaicin and haloperidol use in patients with CHS [22, 32]. Three retrospective studies were short-term, with small sample sizes, without a standardized reporting of outcomes and subject to the risk of bias found in Tables 3 and 4 [24, 25, 28]. Conclusions made were limited due to the low-quality of available evidence. Additionally, some of the statistically significant studies did not measure symptom relief, instead looked at the reduced LOS in hospitals [23-25, 28, 31]. Furthermore, LOS in the ED was used to measure the stabilization of N/V symptoms; however, it was not a marker of CHS cure. In addition to the lack of controlled studies, most of the articles published on CHS were descriptive case reports $[20,23,26,29-31,33-35]$. This anecdotal evidence is important clinically; however, CHS and its management options need to be viewed in the broader context of controlled research. Many different treatments and dosages have been reported among case studies, which may not be generalized to the wider population. It is uncertain whether other adverse effects, rather than N/V, may have arisen from cannabinoid administration.

\section{Further Research}

Due to the global acceptance of medicinal cannabis, further studies should be conducted to fully understand both the beneficial and detrimental effects of cannabinoid drugs, as well as the consequences of its prolonged use and increased concentrations of cannabinoids. RCTs with larger sample sizes and longer follow-ups are warranted. Precise diagnostic criteria for CHS should be postulated where duration and dose of cannabis are predetermined, especially in older adults or patients with renal impairment. Specific genetic variations such as the P450 enzyme polymorphism can also be further evaluated to determine the predisposition for CHS among users. The presented side effects of cannabinoid drugs suggest that further studies are needed to evaluate the safe concentrations of cannabinoid drugs. Furthermore, the data on benzodiazepine use in older populations with $\mathrm{CHS}$ are insufficient and based only on case reports; as a result, safe translation of the existent evidence to clinical practice is unclear and requires further investigation [34].

\section{Conclusions}

With the emergence of cannabis and its widespread usage in various settings, clinicians and users should be more aware of the long-term effects of cannabinoids. CHS is a potential side effect of prolonged cannabis use, causing major distress to consumers. While synthetic cannabinoids have been accepted as one of the main drugs to relieve $\mathrm{N} / \mathrm{V}$, their dosage and duration of administration have not been thoroughly investigated long term. This systematic review alerts the possible outcomes of cannabis use and explores the available management options of CHS. The focus of this review is to stress the importance of rapid recognition, diagnosis, and the available treatment options in adults and older populations. Careful consideration is imperative in older individuals where comorbidities and pharmacological interacts can mask or exacerbate CHS. The novel and highlighted unconventional management options for CHS can be solidified as best practice guidelines with future large-scale research initiatives.

\section{Acknowledgments}

The authors acknowledge the following individuals for their technical assistance with manuscript editing: Yasmin Tehrani, Maheen Mujtaba, Katherine Majerovich, Saja Jaberi, and Gina Modarressi.
Med Princ Pract 2022;31:29-38 DOI: $10.1159 / 000520417$
Senderovich/Patel/Jimenez Lopez/Waicus 


\section{Statement of Ethics}

Ethics approval was not required for this study.

\section{Conflict of Interest Statement}

The authors have no conflicts of interest to declare.

\section{Funding Sources}

There was no funding obtained for this review.

\section{Author Contributions}

Helen Senderovich was responsible for the conception, design, drafting, clinical revisions, and final approval of a version to be published. Helen Sendrovich is accountable for all aspects of the published work. Briam Jimenez Lopez was responsible for the drafting of the paper and interpretation of the data. Sarah Waicus was responsible for the drafting of the paper, interpretation of the data, and critical revisions of the paper. Katherine Majerovich was responsible for the drafting of the paper.

\section{Data Availability Statement}

All data generated or analyzed during this study are included in this article and its supplementary material files. Further enquiries can be directed to the corresponding author.

\section{References}

1 Hjorthoj C, Larsen MO, Starzer MSK. Annual incidence of cannabis-induced psychosis, other substance-induced psychoses and dually diagnosed schizophrenia and cannabis use disorder in Denmark from 1994 to 2016. Psychol Med. 2019;51(4):1-6.

2 United Nations Office on Drugs and Crime. World drug report 2020: 2 - drug use and health consequences. Vienna: UNODC; 2020.

3 Small E, Cronquist A. A practical and natural taxonomy for cannabis. Taxon. 1976;25(4): 405-35.

4 Perisetti A, Gajendran M, Dasari CS, Bansal P, Aziz M, Inamadar S, et al. Cannabis hyperemesis syndrome: an update on the pathophysiology and management. Ann Gastroenterol. 2020;33(6):571-8.

5 Galli JA, Sawaya RA, Friedenberg FK. Cannabinoid hyperemesis syndrome. Curr Drug Abuse Rev. 2011;4(4):241-9.

6 Bajgoric S, Samra K, Chandrapalan S, Gautam N. Cannabinoid hyperemesis syndrome: a guide for the practicing clinician. BMJ Case Rep. 2015;2015:bcr2015210246.

7 Hopkins CY, Gilchrist BL. A case of cannabinoid hyperemesis syndrome caused by synthetic cannabinoids. J Emerg Med. 2013; 45(4):544-6.

8 Stanghellini V, Chan FK, Hasler WL, Malagelada JR, Suzuki H, Tack J, et al. Gastroduodenal disorders. Gastroenterology. 2016;150: 1380-92.

9 Van Sickle MD, Oland LD, Ho W, Hillard CJ, Mackie K, Davison JS, et al. Cannabinoids inhibit emesis through CB1 receptors in the brainstem of the ferret. Gastroenterol. 2001; 121(4):767-74

10 Gunasekaran N, Long LE, Dawson BL, Hansen GH, Richardson DP, Li KM, et al. Reintoxication: the release of fat-stored delta(9)tetrahydrocannabinol (THC) into blood is enhanced by food deprivation or ACTH exposure. Br J Pharmacol. 2009;158(5):13307.

Management of Cannabis Hyperemesis Syndrome
11 Naef M, Curatolo M, Petersen-Felix S, Arendt-Nielsen L, Zbinden A, Brenneisen R. The analgesic effect of oral delta-9-tetrahydrocannabinol (THC), morphine, and a THC-morphine combination in healthy subjects under experimental pain conditions. Pain. 2003;105(1-2):79-88.

12 Del Mar Ramirez Fernandez M, De Boeck G, Wood M, Lopez-Rivadulla M, Samyn N. Simultaneous analysis of THC and its metabolites in blood using liquid chromatographytandem mass spectrometry. J Chromatogr B Analyt Technol Biomed Life Sci. 2008;875(2): 465-70.

13 Drummer OH. Postmortem toxicology of drugs of abuse. Forensic Sci Int. 2004;142(23):101-13.

14 Nasser Y, Woo M, Andrews CN. Cannabis in gastroenterology: watch your head! a review of use in inflammatory bowel disease, functional gut disorders, and gut-related adverse effects. Curr Treat Options Gastroenterol. 2020:1-12. Epub ahead of print.

15 Kim HG, Moon J, Dixon H, Tullar P. Recurrent nausea and vomiting in a pregnant woman with chronic marijuana use. Case Rep Obstet Gynecol. 2018;2018:9746062.

16 Bonnet U. An overlooked victim of cannabis. Clinical Neuropharmacol. 2016;39(1):53-4.

17 Sterne JAC, Hernán MA, Reeves BC, Savović J, Berkman ND, Viswanathan M, et al. ROBINS-I: a tool for assessing risk of bias in nonrandomized studies of interventions. BMT. 2016;355:14919.

18 Sterne JAC, Savović J, Page MJ, Elbers RG, Blencowe NS, Boutron I, et al. RoB 2: a revised tool for assessing risk of bias in randomised trials. BMJ. 2019;366:14898.

19 Richards JR, Lapoint JM, Burillo-Putze G. Cannabinoid hyperemesis syndrome: potential mechanisms for the benefit of capsaicin and hot water hydrotherapy in treatment. Clin Toxicol. 2018;56(1):15-24.
20 Portman D, Donovan KA. Cannabinoid hyperemesis syndrome: a case report of a confounding entity in oncology care. J Oncol Pract. 2018;14(5):333-4.

21 McConachie SM, Caputo RA, Wilhelm SM, Kale-Pradhan PB. Efficacy of capsaicin for the treatment of cannabinoid hyperemesis syndrome: a systematic review. Ann Pharmacother. 2019;53(11):1145-52.

22 Dean DJ, Sabagha N, Rose K, Weiss A, France J, Asmar T, et al. A pilot trial of topical capsaicin cream for treatment of cannabinoid hyperemesis syndrome. Acad Emerg Med. 2020; 27(11):1166-72.

23 Hafez ZT, Liss DB, Schwarz ES, Mullins ME. Capsaicin cream in the treatment of cannabinoid hyperemesis syndrome: relief from the "joint" pain. Clin Toxicol. 2017;55(5): 443.

24 Wagner S, Hoppe J, Zuckerman M Schwarz K, McLaughlin J. Efficacy and safety of topical capsaicin for cannabinoid hyperemesis syndrome in the emergency department. Clin Toxicol. 2020;58(6): 471-5.

25 Yusuf HM, Geier C, Staidle A, Montoy JCC. Efficacy of topical capsaicin for the treatment of cannabinoid hyperemesis syndrome: a retrospective cohort study. Am J Emerg Med. 2021;43:142-8

26 Aziz A, Waheed T, Oladunjoye O, Oladunjoye A, Hanif M, Latif F. Topical capsaicin for treating cannabinoid hyperemesis syndrome. Case Rep Gastrointest Med. 2020;2020: 8868385.

27 Furyk JS, Meek RA, Egerton-Warburton D. Drugs for the treatment of nausea and vomiting in adults in the emergency department setting. Cochrane Database Syst Rev. 2015;9: CD010106.

28 Lee C, Greene SL, Wong A. The utility of droperidol in the treatment of cannabinoid hyperemesis syndrome. Clin Toxicol. 2019; 57(9):773-7. 
29 Kheifets M, Karniel E, Landa D, Vons SA, Meridor K, Charach G. Resolution of cannabinoid hyperemesis syndrome with benzodiazepines: a case series. Isr Med Assoc J. 2019; 21(6):404-7.

30 Inayat F, Virk HU, Ullah W, Hussain Q. Is haloperidol the wonder drug for cannabinoid hyperemesis syndrome? BMJ Case Rep. 2017; 2017:2016218239.

31 Witsil JC, Mycyk MB. Haloperidol, a novel treatment for cannabinoid hyperemesis syndrome. Am J Ther. 2017 Jan/Feb;24(1):e64-7.

32 Ruberto AJ, Sivilotti MLA, Forrester S, Hall AK, Crawford FM, Day AG. Intravenous haloperidol versus ondansetron for cannabis hyperemesis syndrome (HaVOC): a randomized, controlled trial. Ann Emerg Med. 2021; 77(6):613-9.

33 Jones JL, Abernathy KE. Successful treatment of suspected cannabinoid hyperemesis syndrome using haloperidol in the outpatient setting. Case Rep Psychiatry. 2016;2016: 3614053.

34 Richards JR, Dutczak O. Propranolol treatment of cannabinoid hyperemesis syndrome: a case report. J Clin Psychopharmacol. 2017; 37(4):482-4.

35 Parvataneni S, Varela L, Vemuri-Reddy SM, Maneval ML. Emerging role of aprepitant in cannabis hyperemesis syndrome. Cureus. 2019;11(6):e4825.
36 Soota K, Lee Y-J, Schouweiler K, Keeney M, Nashelsky M, Holm A. Cases of death secondary to cannabinoid hyperemesis syndrome. Am J Gastroenterol. 2016;111:S1063.

37 Vinette B, El-Akhras A, Mrad H, Chicoine G, Bilodeau K. Reasons for cannabis use, routes of administration and context of use in oncology: a scoping review. In: MASCC/ISOO Annual Meeting 2021 [conference proceedings on the Internet]; 2021 Jun 24; Virtual. 2021.

38 Waissengrin B, Urban D, Leshem Y, Garty M, Wolf I. Patterns of use of medical cannabis among Israeli cancer patients: a single institution experience. J Pain Symptom Manage. 2015;49(2):223-30

39 Pergolizzi JV, Taylor R, Lequang JA, Zampogna G, Raffa RB. Concise review of the management of iatrogenic emesis using cannabinoids: emphasis on nabilone for chemotherapy-induced nausea and vomiting. Cancer Chemother Pharmacol. 2017;79:467-77.

40 Choi CH, Kim MK, Park J, Yoon A, Kim H-J, Lee Y-Y, et al. Safety and efficacy of aprepitant, ramosetron, and dexamethasone for chemotherapy-induced nausea and vomiting in patients with ovarian cancer treated with paclitaxel/carboplatin. Support Care Cancer. 2014;22(5):1181-7.
41 Duran M, Pérez E, Abanades S, Vidal X, Saura $\mathrm{C}$, Majem $\mathrm{M}$, et al. Preliminary efficacy and safety of an oromucosal standardized cannabis extract in chemotherapy-induced nausea and vomiting. Br J Clin Pharmacol. 2010; 70(5):656-63.

42 World Health Organization. Palliative care [Internet]. 2018 Feb 19 [cited May 4]. Available from: https://www.who.int/news-room/ fact-sheets/detail/palliative-care.

43 Katsumata N. Docetaxel: an alternative taxane in ovarian cancer. Br J Cancer. 2003;89: S9-15.

44 Richards JR, Lapoint JM, Burillo-Putze G. Cannabinoid hyperemesis syndrome: potential mechanisms for the benefit of capsaicin and hot water hydrotherapy in treatment. Clin Toxicol. 2018;56(1):15-24.

45 Fong TG, Tulebaev SR, Inouye SK. Delirium in elderly adults: diagnosis, prevention and treatment. Nat Rev Neurol. 2009;5(4):210-20.

46 Goldman JG, Holden S. Treatment of psychosis and dementia in Parkinson's disease. Curr Treat Options Neurol. 2004;16(3):281.

47 Albouaini K, Andron M, Alahmar A, Egred M. Beta-blockers use in patients with chronic obstructive pulmonary disease and concomitant cardiovascular conditions. Int J Chron Obstruct Pulmon Dis. 2007;2(4):535-40. 